\title{
CONTIGO NO SE PUEDE JUGAR ${ }^{1}$
}

\author{
Rodolfo Villa Valencia ${ }^{2}$
}

$\mathrm{E}$ so depende - dijo David y abrió el maletín. Sacó un marcador y lo destapó. Lo apoyó contra la pared e hizo un círculo del tamaño de una moneda. Miró hacia la puerta para cerciorarse de no haber sido visto por su madre. Después añadió-: ¿Ves esta mancha?

- Sí — asintió Saúl.

-Bien. Puede ser de este tamaño, o sea pequeño — aseguró. Luego hizo un círculo de mayor tamaño que el anterior-. O más grande. Eso depende.

— ¿De qué? -interrogó Saúl sin entender ni una sola palabra.

-De si es con un revólver, un fusil o una escopeta.

A las ocho en punto doña Abigaíl, su madre, servía la comida. De modo que, dejando de lado su conversación, David y Saúl se sentaron en la mesa. Los jueves eran fríjoles, al almuerzo y la comida. La señora se fijó en las manos de David.

- Ve a lavarte las manos, cochino — le dijo, pegándole suavemente en la cabeza.

Saúl sonrió sin que su madre lo viera. Siempre que quería burlarse de su hermano mayor tenía que hacerlo a escondidas para evitarse un castigo. Para todos en la casa estaba claro quién era el preferido.

David regresó y se sentó. Revolvió la comida y levantó una cucharada. La miró. Se le ocurrió que los fríjoles servirían para explicarle mejor a Saúl y, sin que su mamá lo viera, se llevó

${ }^{1}$ Tomado de Villa V., R. (2012). Mañana al medio día. Gobernación de Norte de Santander: Cúcuta.

${ }^{2}$ Licenciado en literatura de la Universidad del Valle, Cali. Ha publicado en revistas nacionales e internacionales, entre ellas Revista Universidad de Antioquia y revista Hybrido. Ganador de varios concursos a nivel nacional, entre ellos XII Concurso Nacional de Cuento “Jorge Gaitán Durán”, Cúcuta, 2011. 
algunos granos al bolsillo del pantalón. Antes de terminar la comida guardó más.

Terminada la cena fueron a lavarse los dientes. Doña Abigaíl los revisó. Sin problemas. Preguntó por las tareas. Dijeron que ya las habían hecho.

- Mira — le dijo David a su hermano estando en el cuartocon estos te explico mejor.

—¿Qué es? — preguntó Saúl.

—Fríjoles. Los saqué de la comida.

Eran en total dieciséis granos. Así que hizo tres grupos: uno de ocho, otro de cinco y otro de tres.

—Pon cuidado — dijo. Aplastó el primer grupo-. Así debe ser el de un fusil. Dicen que cuando sale, deja un hueco inmenso.

Saúl cerró la puerta del cuarto. David aplastó los otros dos grupos y preguntó:

- ¿Entendiste?

— Tengo una idea — dijo Saúl. Fue a la puerta y la abrió. Se fijó en el corredor para cerciorarse de que doña Abigaíl no andaba por ahí.

—Cuál? —dijo David.

- ¿Te acuerdas que el otro día vimos al tío Alejandro guardando una pistola en el cuarto de herramientas?

David lo miró. Le dijo que bajara la voz. Apagó la luz y se metió bajo la cobija. Invitó a su hermano a hacer lo mismo.

— ¿Qué pasa con eso? —interrogó David.

- Pues que podemos, al menos, saber cómo es el de una pistola. ¿No te parece?

—Y cómo vamos a saber — respondió David—. ¿A qué le vamos a disparar?

—Es lo de menos — susurró Saúl—. Lo importante es tenerla con nosotros, ya veremos lo demás.

Se levantaron sin encender la luz. Abrieron la puerta. Acordaron que primero saldría Saúl, porque él fue el de la idea. Se deslizaron sin afanes por el corredor. Pasaron por el cuarto de 
su madre y se alarmaron al ver la luz encendida. Se asomaron. Ya sabían qué excusa dar en caso de ser sorprendidos, pero doña Abigaíl había caído vencida por el cansancio acumulado del día, y dormía con las gafas puestas y la Biblia abierta sobre el pecho.

Bajaron las gradas. Saúl tropezó en el último escalón y David lo reprendió. Continuaron camino a la cocina: a un lado de esta quedaba el cuarto de herramientas. Abrieron la puerta y David fue directo al baúl donde su tío guardaba el taladro y otras cosas. Tomaron el arma y David la guardó en la pretina del pijama.

— ¿Qué tal? — preguntó. Se llevó las manos a la cintura-. Parezco un vaquero de esos de la televisión. ¿O no?

Saúl lo miró.

—Pareces más bien un ladrón de carteras — dijo y sonrió tapándose la boca.

Cerraron la puerta y regresaron al cuarto con el mismo sigilo con que habían ido. Cuando pasaron por el cuarto de la señora, notaron que ya la lámpara había sido apagada. Entraron a la habitación. Primero David; después Saúl.

—Ahora sí —dijo David.

-Ahora sí, pero ¿cómo vamos a hacer? — pregunto Saúl.

Sintieron pasos en el corredor. Se metieron bajo la cobija. Doña Abigaíl abrió la puerta y ojeó dentro del cuarto. Cerró y fue a acostarse nuevamente.

- ¿Ya?

- Sí — asintió David.

— Tenemos que dispararla y no sabemos —inquirió Saúl, mirando a su hermano sacándose la pistola.

-Yo sí sé - aseguró David.

- ¿Y dónde aprendiste?

—En la televisión. Además es como las de juguete: se jala aquí y listo.

Saúl fue hacia la puerta y la aseguró.

— Haremos mucho ruido — dijo. 
- No. colocamos una almohada y eso evita que suene duro.

— ¿Y eso dónde lo aprendiste? Imagino que también en la televisión — dijo Saúl, pasándole una almohada a David.

-Esta no; la otra que tiene más espuma.

—Toma — dijo Saúl.

- Acuéstate —ordenó David.

-No.

-Gallina.

—Estas son balas de verdad —increpó Saúl.

— ¿Cómo se te ocurre? — dijo David. Agregó—: Son como las de la televisión. ¿Acaso no has visto que los actores nunca se mueren?

—Mamá no me deja ver televisión a mí — dijo Saúl—. Como a ti.

-Porque yo soy el mayor.

—Pero yo soy mejor que tú en colegio — dijo Saúl—. Y le hago caso a mamá.

-Eso no importa. Cuando seas grande te dejará, ya verás aseguró David-. Ahora créeme. Las balas de las pistolas son de salva, o algo así. Eso dijo el tío.

Saúl se acostó. David colocó la almohada en la cabeza de su hermano e intentó disparar. No pudo. Puso, entonces, los dedos índices juntos, como había visto en la televisión, y apretó el gatillo. Oyó la bala salir. Sintió un jalonazo. Escuchó a su madre salir del cuarto. Se acostó al lado de su hermano.

—No hagas bulla que mamá despertó — dijo.

Doña Abigaíl intentó abrir la puerta del cuarto. No pudo. Llamó a David. No respondió. Llamo a Saúl. Tampoco. Regresó a su habitación.

—Saúl... Saúl... — susurró David. Metió la pistola bajo el colchón. Se volteó y abrazó a su hermano. Lo besó en la mejilla, como todas las noches, y añadió-: El problema es que te duermes muy rápido. Contigo no se puede jugar. 